\title{
Drowning risks to epileptic children: a study from Hawaii
}

\author{
JOHN PEARN, ROBERT BART, RONALD YAMAOKA
}

British Medical fournal, 1978, 2, 1284-1285

\section{Summary and conclusions}

The role of epileptiform seizures in causing drowning and near-drowning among children was studied by examining the case reports of all 140 childhood immersion accidents that occurred in an area of Hawaii over five years. Four of the 140 immersion accidents were caused partly by epileptiform seizures, but none were fatal. The combined results of the Hawaiian and Brisbane studies (total population studied over five years 1600000 ) showed that no epileptic children died from accidents in the sea or in swimming pools; and the $2.9 \%$ incidence of immersion accidents due to seizures in the Hawaiian study compares well with the incidence found in other series.

If an epileptic child is mentally normal, well controlled with anticonvulsants, and supervised in the water then the risk of drowning is very small.

\section{Introduction}

An Australian study of an epileptic child's risk of drowning showed that the potential risk was increased over that of normal children in relative terms but was still very small. It was concluded that if the attacks were well controlled and there was effective supervision "epileptic children may swim with confidence." No epilepsy-induced drowning or near-drowning occurred in epileptic children who had adequate blood concentrations of anticonvulsants. Similar experience was reported from a large epilepsy diagnostic and treatment centre in Baltimore, ${ }^{2}$ but British experience does not necessarily parallel this. ${ }^{3}$ As denial of swimming is such a limitation for any child, epileptic or not, we studied the subject further in an attempt to provide more hard data on the risks involved.

We reviewed the case records of all children who drowned or who were admitted to hospital after near-drowning in the Island of Oahu, Hawaii, in 1973-7. The area is legendary for the amount and extent of both sea bathing and freshwater swimming (principally swimming pools) and has been the basis for several large epidemiological studies of immersion ${ }^{4}$ and surfing

University of Queensland, Brisbane, Queensland, Australia JOHN PEARN, MD, FRACP, reader in child health

Kauikeolani Children's Hospital, Honolulu, Hawaii

ROBERT BART, MD, paediatric neurologist

Tripler US Army Medical Centre, Hawaii

RONALD YAMAOKA, MD, consultant neurologist accidents. ${ }^{5}$ We report here a study to assess the contribution that epilepsy might make to serious immersion accidents among children.

\section{Methods}

The population of the Island of Oahu is concentrated in the city of Honolulu (resident population of $680000^{6}$ ). All victims of serious immersion accidents are treated in hospital in Honolulu itself, and we studied the records of five hospitals which manage sick children (Kauikeolani Children's Hospital, Kapiolani Medical Centre, Queen's Medical Centre, Kaiser Foundation Medical Centre, and Tripler US Army Hospital) to trace all childhood victims of immersion accidents. Complete searches of the confidential coroner's and forensic files of the Chief Medical Examiner, City and County of Honolulu, were also completed (made possible by the kindness and encouragement of Dr Richard Wong). A total of 31 children ( $0-15$ years) had drowned over the survey period; a further 109 were admitted to hospital after a serious immersion accident in either salt or fresh water but subsequently survived. Seventy-five of these survivors were both unconscious and apnoeic when extracted from the water. Full case details were available for each of these 140 consecutive unselected cases.

\section{Results}

The case reports showed that four $\left(2 \cdot 9^{\prime \prime}{ }_{0}\right)$ of the 140 children had had seizures in the water and had nearly drowned.

Case 1-This 15-year-old boy with a known seizure disorder was found comatose by lifeguards at a busy swimming beach. He was on phenytoin $100 \mathrm{mg}$ four times a day. He responded rapidly to resuscitation and was discharged after four days in hospital.

Case 2-This 9-year-old epileptic boy was found on the bottom of his own freshwater swimming pool. He was receiving diazepam, phenobarbitone, and cyproheptadine. He regained consciousness after several minutes of vigorous resuscitation and was discharged without sequelae after three days in hospital.

Case 3-This grossly retarded (IQ - 50) 12-year-old epileptic boy apparently had a fit in the water and was found on the bottom of a chlorinated school swimming pool. He was semi-comatose but not fully apnoeic when rescued. He responded well to first-aid measures and was discharged after one day in hospital.

Studies of drowning fatalities and proportion due to epileptiform seizures

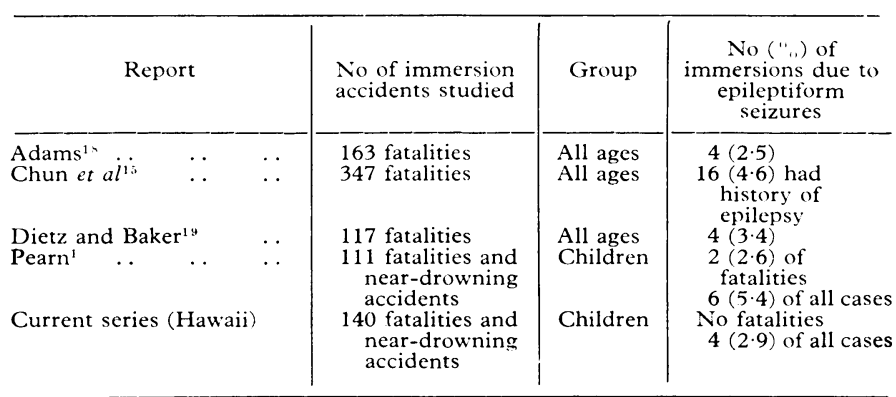


Case 4-This mentally retarded 15-year-old boy with a seizure disorder was found in respiratory distress in the ocean. He was not unconscious and no formal resuscitation was required. He was discharged after four days in hospital.

No epileptic children drowned in Hawaii over the five years or suffered neurological sequelae from an immersion accident. No domestic bath-tub immersion accident occurred to an epileptic or convulsing child during the study period, although such accidents are known to be a special (although small) risk to epileptic patients generally. ${ }^{2}{ }^{-}$The $2 \cdot 9^{\circ}$ " of immersion accidents due to epileptiform seizures in this series is similar to the incidence in other series of drowning accidents (see table)

\section{Discussion}

The combined experience from Hawaii and from the Brisbane drowning study now totals 300 consecutive unselected cases of serious childhood immersion accidents (from a total population of 1600000$)$. In $12\left(4.0^{\circ}{ }_{0}\right)$ of these cases epilepsy was one of several contributing causes. No childhood immersion accident is the result of a single event, but rather the outcome of a chain comprising a number of sequential links, most of which have now been identified. * Bath-tub drowning and near-drowning accidents which happen to epileptic or convulsing children are special cases; these tend to be dangerous immersions, ${ }^{1}{ }^{2} 7$ but preventive measures are well known" and in our experience usually are implemented by parents. There is no place for complacency, however, and all who care for epileptic children should emphasise to parents the potential dangers of the household bath tub.

When bath-tub immersions were excluded there were 274 remaining consecutive immersion accidents available for analysis; in none was there a death due to epilepsy. This further highlights the confidence with which controlled and supervised epileptics can swim. Nine cases $\left(3.3^{\circ}{ }_{0}\right)$ of non-bath-tub immersions from these two combined series were attributable to epileptic seizures, but none resulted in measurable neurological deficit, and all children were discharged from hospital within five days of the accident. There are as yet no reports of plasma anticonvulsant concentrations in epileptic children who suffer fits in the water; such information might show that the risk to epileptic children who are clinically free of attacks and who have adequate blood levels of anticonvulsants is even smaller than that observed for epileptic children as a whole. ${ }^{3}$

Mentally subnormal children with epilepsy are particularly at risk of all kinds of trauma, ${ }^{910}$ but if they are adequately controlled with anticonvulsants and if effectively supervised there seems to be no reason why even they should not swim.

The pre-diving hyperventilation that adult swimmers sometimes perform in an attempt to achieve prolonged underwater endurance is a dangerous practice at any time. ${ }^{11}$ It has special risks for an epileptic swimmer, but we have not encountered cases of seizures in the water precipitated by this practice among children.

Drowning and near-drowning seem to be less of a threat to the epileptic than other forms of trauma, such as burns, ${ }^{1213}$ but retrospective studies of accidents to epileptics cannot take into full account the degree of exposure to the relative risks. The assessment of exposure to environmental hazards requires prospective studies; to date, all detailed published studies of drowning and childhood epilepsy have used the immersion incident itself as the method of identifying and tracing cases. Using this approach, and assuming that $0.5^{\circ}{ }_{0}$ of the general population are epileptic children, ${ }^{14}$ we calculated from the combined Hawaiian and Brisbane figures that the risk of an immersion accident is less than 1 in 300 epileptic-child-years for all types of water hazard, including baths; the risk is less than 1 in 400 epileptic-child-years for bathing in the sea or swimming pool at the high rates of current exposure in tropical ${ }^{15}$ and subtropical ${ }^{7}$ s countries.

Calculation of the real risk of drowning or near-drowning to various subclasses of epileptic children (those uncontrolled clinically, those who are subnormal, those without adequate blood concentrations of anticonvulsants, etc) must await the publication of prospective series in which epileptic children are followed rather than being found through a drowning accident. Only in this way can adequate allowance be made for varying exposure to water and its combined joys ${ }^{16}$ and potential hazards. ${ }^{1 \text { 7 }}$ Indeed, simply the greater exposure to water hazards may explain the higher relative risk in Australian ${ }^{1}$ than in British ${ }^{3}$ children with epilepsy.

The potential risk (of drowning) to epileptic children is thus increased by a factor of four, but the Brisbane ${ }^{1}$ and Hawaiian studies have shown that this risk is not realised if care is exercised by doctors and parents. We conclude from this further total population study that an epileptic child may swim with confidence provided he is well controlled (seizure free for one year), has an adequate blood anticonvulsant concentration, and is supervised in the water by an adult who knows he has had seizures.

We thank the paediatricians of the City and County of Honolulu for access to case records of children under their care. In particular, we thank Dr Richard Wong, Dr Sherrel Hammar, Colonel Joseph Brown III, Dr Yi-Chuan Ching, and Professor Ted Hsia.

Requests for reprints should be addressed to Dr J Pearn, Department of Child Health, Royal Children's Hospital, Herston, Brisbane, Australia 4029.

\section{References}

${ }^{1}$ Pearn, J H, British Medical fournal, 1977, 1, 1510.

2 Livingston, S, Pauli, L L, and Pruce, I, British Medical fournal, 1977, 3, 515.

${ }^{3}$ Neville, B G R, British Medical fournal, 1977, 2, 122.

4 Barrett, O, and Martin, C M, Military Medicine, 1971, 136, 439.

Allen, R H, et al, fournal of the American Medical Association, 1977, 237, 668.

${ }^{6}$ Hawaii Department of Health, Population Characteristics of Hawaii, 1978. Issue No 9. Honolulu, USA, Research and Statistics Office (State Department of Health), 1977.

? Pearn, J, and Nixon, J, Medical fournal of Australia, 1977, 1, 211.

${ }^{8}$ Pearn, J, and Nixon, J, Medical fournal of Australia, 1977, 1, 616.

9 Berggren, S M, Acta Paediatrica Scandinavica, 1972, 62, 289.

10 Williams, C E, Developmental Medicine and Child Neurology, 1973, 15, 660.

${ }^{11}$ Craig, A B, fournal of the American Medical Association, 1961, 176, 255.

12 Tempest, M N, British Medical fournal, 1956, 1, 1387.

${ }_{13}$ Richards, E H, Epilepsia, 1968, 9, 127.

14 Rose, S W, et al, Epilepsia, 1973, 14, 133.

${ }^{15}$ Chun, B, Okihiro, M M, and Hale, R W, Hawaii Medical fournal, 1973, 32, 92.

16 British Medical fournal, 1976, 1, 1489.

17 Pearn, J H, Nixon, J, and Wilkey, I, Medical fournal of Australia, 1976, 2, 942.

18 Adams, A I, Medical fournal of Australia, 1966, 2, 1257.

19 Dietz, P E, and Baker, S P, American fournal of Public Health, 1974, 64, 303.

(Accepted 18 August 1978)

Has any relationship between genital candidiasis and candidal septicaemia been defined?

There is no established relationship between genital candidiasis and candidal septicaemia. Genital candidiasis is common, and in healthy subjects, and most sufferers are, it does not cause candidaemia. Candidal septicaemia occurs in very ill patients, many of them with immunological deficiencies, some the result of deliberate immunosuppressive treatment. The two common factors that these patients share are the presence of intravenous lines, providing a direct portal of entry, and the excessive use of antibacterial antibiotics, producing a selective effect for candida overgrowth. ${ }^{1}$ The site of this overgrowth can be almost anywhere in the body but is usually found in the colonic flora.

${ }^{1}$ Secling, M S, et al, Progress in Cardiovascular Disease, 1974, 17, 125. 